\title{
Patients' Perceptions Towards the Participation of Medical Students in their Care
}

"Mohammed Al Ghobain, Abdullah Alghamdi, Ala Arab, Nora Alaem, Turki Aldress, Mead Ruhyiem

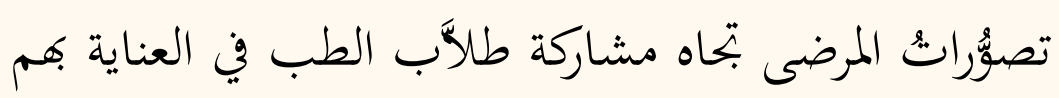

محمّّ الغبين، محمّّ الغامدي، علاء عرب، نورا علايم، تركي الدريس، ميعاد رحيم

ABSTRACT: Objectives: Patient interaction is a vital part of healthcare training. This study aimed to investigate patients' perceptions of the participation of medical students in their care. Methods: This descriptive cross-sectional study was conducted between October 2014 and March 2015 among 430 patients admitted to the medical and surgical wards at the King Abdulaziz Medical City, Riyadh, Saudi Arabia. An Arabic questionnaire was designed to assess the demographic characteristics of the patients and their perceptions of students' participation in their medical care. Results: A total of 416 patients completed the survey (response rate: 97\%). Overall, 407 patients (98\%) acknowledged the educational benefit of involving medical students in their care. A total of 368 patients (88\%) had no objection to a medical student being involved in their care. Of these, $98 \%$ were willing to be asked about their medical history by medical students, $89 \%$ would permit physical examinations by medical students and $39 \%$ preferred that the gender of the medical student match their own. Education level $(P<0.003)$, a positive prior experience with a medical student $(P<0.001)$ and perception of the medical students' attitudes $(P<0.001)$ had a significant effect on patients' acceptance of medical students participating in their care. Conclusion: In general, the patients had a positive perception of medical students, with most patients acknowledging the educational benefit of student participation in patient care. As patients' perceptions of students' professionalism, confidence and respect for privacy were significantly related to acceptance of care, education on these aspects should be a priority in medical curricula.

Keywords: Patients; Perceptions; Attitudes; Medical Students; Medical Education; Saudi Arabia.

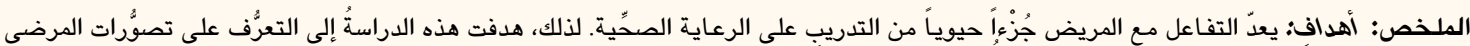

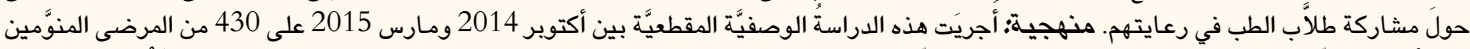

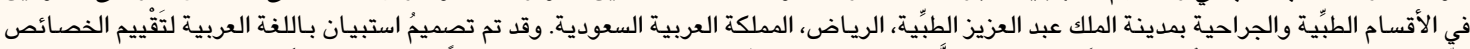

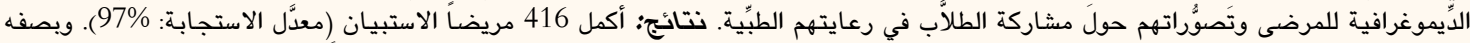

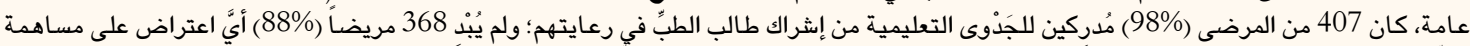

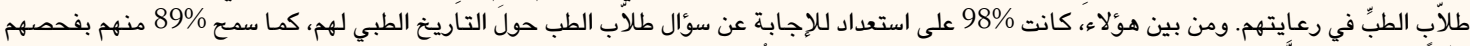

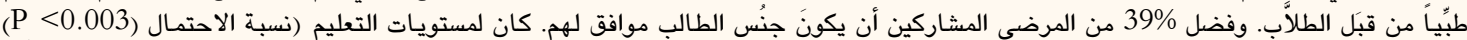

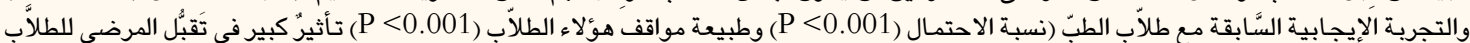

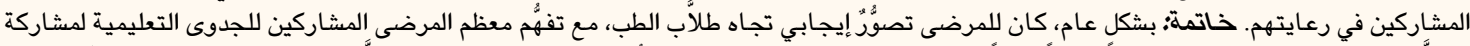

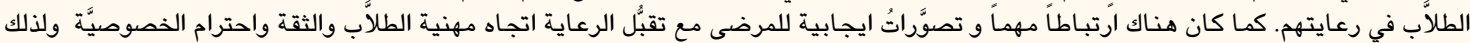

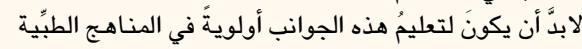

كلمات مفتاحية: المرضى؛ تصور؛ موقف؛ طلاب الطب؛ التعليم الطبي؛ المملكة العربية السعودية.

\section{ADVANCES IN KNOWLEDGE}

The majority of the patient cohort of this study demonstrated positive attitudes towards the involvement of medical students in their care. Among those with no objection to medical student participation, most patients permitted students to take their medical histories and perform physical examinations.

Patient education levels were significantly associated with positive attitudes towards medical student participation.

Moreover, positive prior experiences with a medical student and perceptions of the students' attitudes had a significant effect on patient acceptance of student involvement in their care.

\section{Application to Patient Care}

- Research indicates that student-patient interactions are necessary to improve medical students' competencies.

The findings of this study indicate that physicians should not hesitate to involve medical students in patient care, including historytaking and physical examinations.

However, the majority of patients preferred that physicians remain present during interactions with medical students, particularly during physical examinations. This would serve to increase patient safety and minimise the rejection of medical students' involvement in patient care. 
I T IS VITAL THAT MEDICAL STUDENTS ARE ABLE to interact with patients from an early stage in their medical education. ${ }^{1,2}$ In order to accomplish this, medical schools have employed a variety of methods including practice scenarios with simulations or mannequins. ${ }^{3,4}$ Nevertheless, previous studies have found that allowing medical students contact with real patients is fundamental to enhancing their clinical skills prior to graduation., 5 Several studies have evaluated patients' perceptions of medical students in a range of medical specialties and have indicated that patients have a generally accepting attitude towards the participation of medical students in their care.,7 However, certain factors or characteristics may affect patient attitudes towards medical students, such as previous experiences with medical students, education level, nature of the medical issue and the students' genders and attitudes. ${ }^{2,3,7-9}$ To the best of the authors' knowledge, only two cross-sectional studies regarding patients' attitudes towards the participation of medical students in their care have yet been conducted in Saudi Arabia., ${ }^{3,10}$ Abdulghani et al. found that $64 \%$ and $90.1 \%$ of 492 patients were accepting of medical students attending physical examinations and of students taking their medical histories, respectively, while Bukhari et al. observed that $80 \%$ of 102 outpatient respondents were willing to let medical students participate in their treatment. ${ }^{3,10}$

The King Abdulaziz Medical City (KAMC) is a tertiary healthcare centre in Riyadh, Saudi Arabia, with a patient capacity of over 800 beds. In 2004, KAMC founded the College of Medicine which later became the King Saud bin Abdulaziz University for Health Sciences; the university currently utilises KAMC as an educational institution for clinical practice. The current study was designed primarily to evaluate patients' perceptions of medical students' participation in their medical care at KAMC. In addition, patients' prior experiences with medical students, preferences regarding student gender and their willingness to be involved in medical education were assessed.

\section{Methods}

This descriptive cross-sectional study was conducted at KAMC between October 2014 and March 2015. A total of 430 Arabic-speaking adult inpatients of both genders admitted to the medical and surgical wards at KAMC during the study period were included. Patients who were below 18 years old, mentally or critically ill, clinically unstable or who required emergency and/ or ambulatory care were not eligible for inclusion. In addition, long-term and geriatric patients were excluded as students are not usually exposed to these types of patients. The required sample size was determined using a sample size calculator (Raosoft Inc., Seattle, Washington, USA). The recommended sample size was 377 with a $95 \%$ confidence interval, $5 \%$ margin of error and 50\% response distribution; a sample size of 430 patients was chosen in order to mitigate the effect of possible incomplete data. Weekly lists of admitted patients in the medical and surgical wards were provided by the admissions office at KAMC. Systemic sampling began via a randomised start-point and by selecting every fifth patient on the list. Using this method, selected patients who met the inclusion criteria were subsequently invited to participate in the study.

An Arabic language questionnaire was designed to assess the patients' perceptions of medical student participation in their care. The first section elicited the demographic data of the participants, including age, gender, marital status, educational level and current medical problem. The second section involved 12 items regarding the patient's opinion of students' participation in their medical care, their preference for the attending medical students' gender and their perceptions of the students' attitudes. These items were scored using a five-point Likert scale. The final section included two questions to determine the patients' prior experiences with medical students; answers were recorded on a yes/no basis. The questionnaires were distributed among the selected patients by fourthand fifth-year medical students. Patients completed the questionnaire on their own or, if they were incapable of doing so, with the help of the medical students. The medical students then collected the completed questionnaires.

Collected data were entered into an Excel spreadsheet, Version 2010 (Microsoft Inc., Redmond, Washington, USA). The Statistical Package for the Social Sciences (SPSS), Version 21.0 (IBM Corp., Chicago, Illinois, USA) was used to calculate descriptive and comparative statistics. Pearson's Chi-squared test was used to determine associations between categorical variables.

This study was granted ethical approval by the Research Committee at the King Abdullah International Medical Research Center in Riyadh (\#RC12/71). All of the subjects gave informed consent for their inclusion in the study. Confidentiality was ensured in all of the study processes.

\section{Results}

A total of 416 patients participated in the study (response rate: 97\%). The participants ranged in age 
Table 1: Demographic characteristics of inpatients at the King Abdulaziz Medical City, Riyadh, Saudi Arabia $(\mathrm{N}=416)$

$\begin{array}{lc}\text { Characteristic } & \mathbf{n}(\%) \\ \text { Mean age in years } \pm \text { SD } & 52.7 \pm 18.9 \\ \text { Gender } & \\ \text { Male } & 229(55) \\ \text { Female } & 187(45) \\ \text { Marital status } & \\ \text { Married } & 350(84) \\ \text { Unmarried } & 66(16) \\ \text { Education level } & \\ \text { None } & 114(27) \\ \text { Primary and secondary } & 199(48) \\ \text { University } & 103(25) \\ \text { Type of care } & \\ \text { Medical } & 205(49) \\ \text { Surgical } & 211(51) \\ \text { SD = standard deviation. } & \end{array}$

from $18-107$ years old with a mean age of $52.7 \pm 18.9$ years. Males accounted for $55 \%$ of the participants while $84 \%$ were married. Education levels varied, with $27 \%$ of the cohort having had no education at all. Overall, $49 \%$ of the participants were in medical wards while the remainder were in surgical wards [Table 1].

The educational benefit of involving a medical student in their treatment was acknowledged by 407 patients $(98 \% ; P<0.001)$. A total of 368 patients (88\%) stated that they would allow medical students to participate in their medical care $(P<0.001)$. Of the patients who would allow medical students to aid in their care, 362 (98\%) reported that they had no problem being asked about their medical history by medical students $(P<0.001)$. However, only 314 (85\%) of those agreeable to medical student participation would disclose sensitive or personal information related to their health (such as a history of sexually transmitted diseases, substance abuse and genetic diseases) when giving their history to a medical student $(P<0.001)$. Of those allowing medical students to participate in their medical care, 351 patients (95\%) reported that they would not object to a medical student being present during a doctor-administered examination $(P<0.001)$, while 326 patients $(89 \%)$ would agree to be examined by a medical student $(P<0.001)$. The presence of a doctor during history-taking or a physical examination by a medical student was preferred by 357 patients (97\%) among those who would allow medical students to aid
Table 2: Self-reported perceptions regarding medical students' participation in their healthcare among inpatients at the King Abdulaziz Medical City, Riyadh, Saudi Arabia $(\mathrm{N}=416)$

\begin{tabular}{|c|c|c|c|}
\hline \multirow[t]{2}{*}{ Questionnaire item } & \multicolumn{2}{|c|}{ n (\%) } & \multirow{2}{*}{$\begin{array}{c}P \\
\text { value }\end{array}$} \\
\hline & Agree & Disagree & \\
\hline $\begin{array}{l}\text { I accept the participation } \\
\text { of medical students in my } \\
\text { healthcare }\end{array}$ & $368(88)$ & $48(12)$ & $<0.001$ \\
\hline $\begin{array}{l}\text { I believe that the } \\
\text { participation of medical } \\
\text { students in my healthcare } \\
\text { is important in medical } \\
\text { education }\end{array}$ & $407(98)$ & $9(2)$ & $<0.001$ \\
\hline $\begin{array}{l}\text { I agree to be asked by a } \\
\text { medical student about my } \\
\text { medical history* }\end{array}$ & $362(98)$ & $6(2)$ & $<0.001$ \\
\hline $\begin{array}{l}\text { I agree to disclose } \\
\text { personal information } \\
\text { related to my health to a } \\
\text { medical student"* }\end{array}$ & $314(85)$ & $54(15)$ & $<0.001$ \\
\hline $\begin{array}{l}\text { I agree to have a medical } \\
\text { student present when the } \\
\text { doctor is examining me* }\end{array}$ & $351(95)$ & $17(5)$ & $<0.001$ \\
\hline $\begin{array}{l}\text { I agree to be clinically } \\
\text { examined by a medical } \\
\text { student"* }\end{array}$ & $326(89)$ & $42(11)$ & $<0.001$ \\
\hline $\begin{array}{l}\text { I prefer to have the } \\
\text { doctor present when a } \\
\text { medical student is taking } \\
\text { my medical history or } \\
\text { performing a clinical } \\
\text { examination* }\end{array}$ & $357(97)$ & $11(3)$ & $<0.001$ \\
\hline $\begin{array}{l}\text { I prefer to have a medical } \\
\text { student of my gender* }\end{array}$ & $143(39)$ & $225(61)$ & $<0.001$ \\
\hline
\end{tabular}

*Responses include only those patients who accepted the participation of medical students in their care.

in their care $(P<0.001)$. With regards to the gender of the medical student, 143 patients $(39 \%)$ reported that they would prefer the medical student to be of the same gender as themselves [Table 2]. Patients' education levels were strongly correlated with patient acceptance $(P<0.003)$. No other demographic characteristics were significantly associated with patient acceptance [Table 3].

In total, 165 patients (40\%) indicated that they had had a prior experience with medical students; of these, 157 patients (95\%) rated their previous experiences as positive. A total of 143 patients (87\%) perceived the behaviour of medical students to be professional and 144 (87\%) reported that medical students had displayed confidence while treating them. However, five patients (3\%) felt that medical students had not respected their privacy [Table 4]. A positive prior experience with a medical student was significantly associated with patient acceptance of a medical student administering their care $(P<0.001)$. Six of the eight patients $(75 \%)$ who had had a negative prior experience with a medical student stated that they would not allow a 
Table 3: Associations between demographic characteristics and acceptance of medical students' participation in their healthcare among inpatients at the King Abdulaziz Medical City, Riyadh, Saudi Arabia $(\mathrm{N}=416)$

\begin{tabular}{|c|c|c|c|}
\hline \multirow[t]{2}{*}{ Characteristic } & \multicolumn{2}{|c|}{ n (\%) } & \multirow{2}{*}{$\begin{array}{c}P \\
\text { value }\end{array}$} \\
\hline & $\begin{array}{l}\text { Acceptance } \\
\text { of medical } \\
\text { student } \\
\text { participation } \\
(\mathbf{n}=368)\end{array}$ & $\begin{array}{l}\text { Refusal of } \\
\text { medical } \\
\text { student } \\
\text { participation } \\
(n=48)\end{array}$ & \\
\hline Age in years & & & 0.101 \\
\hline $18-44$ & $128(92)$ & $11(8)$ & \\
\hline $45-64$ & $90(83)$ & $18(17)$ & \\
\hline$>65$ & 150 (89) & $19(11)$ & \\
\hline Gender & & & 0.172 \\
\hline Male & 207 (90) & $22(10)$ & \\
\hline Female & $161(86)$ & $26(14)$ & \\
\hline \multicolumn{4}{|l|}{ Marital status } \\
\hline Married & $308(88)$ & $42(12)$ & 0.497 \\
\hline Unmarried & $60(91)$ & $6(9)$ & \\
\hline Type of care & & & 0.182 \\
\hline Medical & $177(86)$ & $28(14)$ & \\
\hline Surgical & $191(91)$ & $20(9)$ & \\
\hline Education level & & & $<0.003$ \\
\hline None & $91(80)$ & $23(20)$ & \\
\hline $\begin{array}{l}\text { Primary and } \\
\text { secondary }\end{array}$ & $184(92)$ & $15(8)$ & \\
\hline University & $93(90)$ & $10(10)$ & \\
\hline
\end{tabular}

student to care for them. Medical students' perceived attitudes in terms of professionalism, respect for patient privacy and confidence were significantly related to the patients' acceptance of medical student participation $(P<0.001)$.

\section{Discussion}

Contact with patients is vital to improving medical students' education and expanding their knowledge of various medical specialties. ${ }^{1,2}$ However, patients' perceptions of care can potentially be affected by the presence or involvement of medical students; this may, in turn, influence the students' educational experience. ${ }^{11}$ Ellett et al. found that $88 \%$ of patients attending a student-run clinic were aware that the clinic was run by medical students and $98 \%$ were satisfied with their treatment. ${ }^{12}$ A study conducted at a dermatology clinic in the USA showed a high rate of patient acceptance for medical students regardless
Table 4: Self-reported perceptions of medical students among inpatients with previous experiences of medical students at the King Abdulaziz Medical City, Riyadh, Saudi Arabia (N = 165)

\begin{tabular}{lcccc} 
Questionnaire item & \multicolumn{3}{c}{ n (\%) } & $\begin{array}{c}\boldsymbol{P} \\
\text { value }\end{array}$ \\
& Agree & Neutral & Disagree & \\
$\begin{array}{l}\text { I felt comfortable } \\
\text { when the medical } \\
\text { student took my } \\
\text { medical history or } \\
\text { performed a clinical } \\
\text { examination }\end{array}$ & $129(78)$ & $32(19)$ & $4(2)$ & $<0.001$ \\
$\begin{array}{l}\text { The medical student } \\
\text { dealt with me in a } \\
\text { professional and } \\
\text { attentive manner }\end{array}$ & $143(87)$ & $21(13)$ & $1(1)$ & $<0.001$ \\
$\begin{array}{l}\text { The medical student } \\
\text { respected my privacy }\end{array}$ & $151(92)$ & $9(6)$ & $5(3)$ & $<0.001$ \\
$\begin{array}{l}\text { The medical student } \\
\text { treated me with } \\
\text { confidence }\end{array}$ & $144(87)$ & $17(10)$ & $4(2)$ & $<0.001$ \\
& & & &
\end{tabular}

of gender and willingness to share private information with students. ${ }^{13}$ The majority of patients in the current study had a positive perception of medical students and would allow medical students to take part in their care; of these, most were willing to share their medical histories with medical students. However, patients were more accepting of a medical student being present during a doctor-performed physical examination than of a medical student performing the examination themselves and most patients preferred that a doctor be present during a student-led historytaking or physical examination session. However, almost two-thirds of the patients indicated that the gender of the medical student was not an issue.

The results of the current study are comparable to those of previous studies conducted in Saudi Arabia. ${ }^{3,10}$ Abdulghani et al. reported lower rates of patient acceptance with regards to medical students taking patient histories and interacting with medical students of a different gender. ${ }^{3}$ However, although patients were aware of their right to refuse medical student participation in their care, most recognised the benefits of accepting student involvement and were agreeable to participating in the students' medical education. ${ }^{3}$ Additionally, patients perceived the role of medical students to be either treating physicians, physician helpers or observers, highlighting the importance of patient awareness regarding the purpose of student participation. ${ }^{3}$ Bukhari et al. noted that $32.4 \%$ of patients preferred to be physically examined by a physician alone; furthermore, $58.5 \%$ of the respondents either agreed or strongly agreed that they would prefer having a medical student of the same gender as themselves. ${ }^{10}$ 
Monnickendam et al. confirmed that $59.7 \%$ and $34 \%$ of Israeli patients, respectively, would allow a student to take their medical history and examine them, as long as the students were supervised by a tutor. $^{14}$ This is in line with the findings of the current study; while most patients in the current study had few reservations in giving their medical histories to students, some felt uncertain in allowing medical students to perform a physical examination. In these situations, practice of patient care using simulated patients and/or mannequins is a valuable method to fill in these skill gaps. ${ }^{3,4}$ Moreover, as the current study found that medical students' perceived attitudes in terms of professionalism, respect for patient privacy and confidence were significantly related to the patients' acceptance of their care, medical schools should incorporate modules on professionalism and patient-doctor relations within the medical curricula, prior to allowing student-patient interactions.

In terms of gender preference, several studies have indicated that male patients are reportedly less comfortable with a female student undertaking history-taking and physical examinations and vice versa. $^{2-4,15}$ In general, the primacy factors cited by patients for refusing medical student care include concerns about confidentiality or privacy, longer visit durations, unease regarding potential mistakes made during treatment and negative previous experiences with medical students., ${ }^{2,9}$ Furthermore, medical students may be barred from working with certain patients due to different religious and cultural backgrounds or gender preferences. ${ }^{5,8}$ The results of a study by Onotai et al. support the notion that patients' perceptions are affected by previous negative experiences with medical students. ${ }^{8}$ The present study also showed that previous experience had an effect on patients' acceptance of medical students. Previous positive experiences make it more likely that patients will comfortably accept medical students' involvement in their care. ${ }^{7,16}$ Such experiences have been found to contribute to lowering patients' sensitivity towards the gender of participating medical students. ${ }^{5}$

Comparable to the results of Malhotra et al., the majority of the patients in the current study acknowledged the educational advantages of medical student involvement in their care. ${ }^{1}$ Other research has also supported this theory; most patients, whether accepting of medical students' involvement in their care or not, appreciate the educational benefit of student participation in care as a means of improving practice as well as in encouraging students to become better doctors ${ }^{8,17}$ Indeed, research has indicated that patients who are appreciative of the importance and benefit of patient-student interactions willingly choose to take part in students' medical education., ${ }^{2,3}$ Despite the low rate of previous experience with medical students, the patients in the current study tended nevertheless to be accepting of medical students' participation in their care. A previous study showed that $77 \%$ of patients felt that they received an improved standard and duration of care when students were involved. ${ }^{15}$

Further studies in medical education are vital to the development of this field; in particular, patients' perceptions of their interactions with medical students require more detailed evaluation. The results of the present study may be beneficial to medical schools in evaluating their own patient-student interactions. Points of investigation unique to this study included the random sampling of adult patients across both genders and various medical specialties as well as the inclusion of forms of student-patient interaction that were not explored in previous local studies, such as medical students' professionalism, respect for patient privacy and confidence. However, this study has several limitations. Due to its nature as a crosssectional study, there was possible bias in reporting results. Moreover, potential bias may have been introduced when medical students completed forms on behalf of the patients. The study was also limited to surgical and medical patients and did not include patients from other specialities.

\section{Conclusion}

The majority of the surveyed patients had a positive perception of medical students. Most patients were accepting of medical students' participation in their care and had no objection to giving students their medical history nor to having a student perform their medical examination. However, the vast majority of patients preferred that the doctor remain present with the student when performing these interactions. Most patients who had had a previous experience with medical students rated their experience as positive. As the medical students' perceived professionalism, respect for patient privacy and confidence were significantly related to patients' acceptance of student participation in their care, these social competencies should be a priority in medical curricula. This may, in turn, encourage patients to be more accepting of the participation of medical students in their care.

\section{CONFLICT OF INTEREST}

The authors declare no conflicts of interest. 


\section{References}

1. Malhotra RK, Hosdurga G. Patients' attitudes towards the involvement of medical students during induction of regional anesthesia. Local Reg Anesth 2010; 3:73-6. doi: 10.2147/LRA. S13098.

2. Shah-Khan M, Chowdhry S, Brand MI, Saclarides TJ. Patient attitudes toward medical students in an outpatient colorectal surgery clinic. Dis Colon Rectum 2007; 50:1255-8. doi: 10.1007 /s10350-007-0274-x.

3. Abdulghani HM, Al-Rukban MO, Ahmad SS. Patient attitudes towards medical students in Riyadh, Saudi Arabia. Educ Health (Abingdon) 2008; 21:69.

4. Rizk DE, Al-Shebah A, El-Zubeir MA, Thomas LB, Hassan MY Ezimokhai M. Women's perceptions of and experiences with medical student involvement in outpatient obstetric and gynecologic care in the United Arab Emirates. Am J Obstet Gynecol 2002; 187:1091-100. doi: 10.1067/mob.2002.126284.

5. Racz JM, Srikanthan A, Hahn PM, Reid RL. Gender preference for a female physician diminishes as women have increased experience with intimate examinations. J Obstet Gynaecol Can 2008; 30:910-17. doi: 10.1016/S1701-2163(16)32972-3.

6. O'Flynn N, Rymer J. Women's attitudes to the sex of medica students in a gynaecology clinic: Cross sectional survey. BMJ 2002; 325:683-4. doi: 10.1136/bmj.325.7366.683.

7. Simons RJ, Imboden E, Martel JK. Patient attitudes toward medical student participation in a general internal medicine clinic. J Gen Intern Med 1995; 10:251-4. doi: 10.1007/BF0259 9880.

8. Onotai LO, Asuquo EO, Amadi E, Amadi-Oparelli A, Ali DU. Patients' perception and attitude towards medical students' involvement in patients care at a Nigerian university teaching hospital. Educ Res 2012; 3:732-43.
9. Howe A, Anderson J. Involving patients in medical education. BMJ 2003; 327:326-8. doi: 10.1136/bmj.327.7410.326.

10. Bukhari I, AlAkloby O, Al Saeed W. Patients' attitude towards medical students rotating in the dermatology clinic. Indian J Dermatol 2008; 53:12-14. doi: 10.4103/0019-5154.39734.

11. Simon SR, Peters AS, Christiansen CL, Fletcher RH. The effect of medical student teaching on patient satisfaction in a managed care setting. J Gen Intern Med 2000; 15:457-61. doi: 10.1046/j.1525-1497.2000.06409.x.

12. Ellett JD, Campbell JA, Gonsalves WC. Patient satisfaction in a student-run free medical clinic. Fam Med 2010; 42:16-18.

13. Townsend B, Marks JG, Mauger DT, Miller JJ. Patients' attitudes toward medical student participation in a dermatology clinic. J Am Acad Dermatol 2003; 49:709-11. doi: 10.1067/S01909622(03)00915-0.

14. Monnickendam SM, Vinker S, Zalewski S, Cohen O, Kitai E. Patients' attitudes towards the presence of medical students in family practice consultations. Isr Med Assoc J 2001; 3:903-6.

15. Prislin MD, Morrison E, Giglio M, Truong P, Radecki S. Patients' perceptions of medical students in a longitudinal family medicine clerkship. Fam Med 2001; 33:187-91.

16. Ryder N, Ivens D, Sabin C. The attitude of patients towards medical students in a sexual health clinic. Sex Transm Infect 2005; 81:437-9. doi: 10.1136/sti.2004.014332.

17. Sadıkoglu G. Family medical centre patients' attitudes toward senior medical students' participation in the examinations. Middle East J Fam Med 2007; 5:38-41.

18. Lucas B, Pearson D. Patient perceptions of their role in undergraduate medical education within a primary care teaching practice. Educ Prim Care 2012; 23:277-85. doi: 10.10 80/14739879.2012.11494121. 